\title{
The Way to Achieve Internalization of External Diseconomy of Exploitation of Mineral Resources
}

\author{
Meitian Zhao \\ ${ }^{1}$ China University of Mining and Technology (Beijing), Haidian, Beijing 100083, China \\ ${ }^{2}$ North China Institute of Science and Technology, Sanhe, Hebei 065201, China \\ zhaomt@sina.com
}

\begin{abstract}
Mineral resources, one of the earliest natural objects which human developed and utilized, has played a pivotal role in the process of social and economic development. According to "China's mineral resources policy", more than $92 \%$ primary energy, $80 \%$ industrial raw materials, more than $70 \%$ agricultural production materials come from mineral resources. As quasi-public goods, mineral resources not only bring the economic benefits but also produce strong negative externalities in the process of its development and utilization. The way to achieve internalization of external diseconomy of exploitation of mineral resources utilizing the theory of externality has the great significance to the sustainable development of mineral resources and economic and social.
\end{abstract}

Index Terms - Mineral resources External Diseconomy Internalization

\section{Introduction}

Henry Sidgwick and Alfred Marshall are the pioneering researchers of externality theory. It is generally believed that the theory of economic externality was put forward by the famous economist Marshall, and enriched and developed by his students Arthur Cecil Pigou. In economics, an externality is the cost or benefit that affects a party who did not choose to incur that cost or benefit. [1] It includes two main types: positive externality and negative externality. A positive externality (also called "external economy" or "external benefit") is an action of a product on consumers that imposes a positive effect on a third party. A negative externality (also called "external diseconomy" or "external cost") is an action of a product on consumers that imposes a negative effect on a third party which is mainly related to the environmental consequences of production and use, such as air pollution, water pollution and so on. According to 《China's mineral resources policy $》$, more than $92 \%$ primary energy, $80 \%$ industrial raw materials, more than $70 \%$ agricultural production materials come from mineral resources.[2] As quasi-public goods, mineral resources not only bring the economic benefits but also produce strong negative externalities in the process of its development and utilization. The external costs and benefits are showed in Fig 1.In this paper, the external costs of exploitation of mineral resources are analyzed and some ways are given to internalization it.

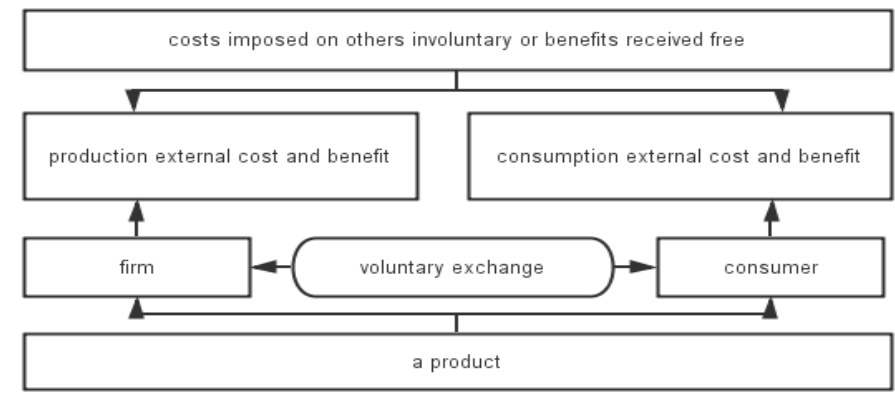

Fig 1: external costs and benefits

2. The Current Situation of the Development of the Mineral Resource and Its Negative Externality in China

A. The Current Situation of the Development of the Mineral Resource in China.

We can see the current development situation of the mineral resource in China from the current development situation of the city of resource in China. According to the data from the data center of IUD-International Institute for Urban Development, Beijing, we can know that among the resourcebased cities, most cities are for coal, petrol, iron mine and copper mine. In the 118 resource-based cities in China, there are 63 coal cities, covering 53\%, 21 forest cities, covering $18 \%, 12$ Nonferrous Metallurgy cities, 9 petrol cities, 8 ferrous metallurgy cities, and 5 other cities, covering $10 \%, 8 \%, 7 \%$ and $4 \%$ respectively. There are 92 mineral resource mining cities, covering $77.97 \%$. From these, we can see that the mineral resource enterprises are mostly located in the resource-based cities, and mining area is at the core position in the development of the resource-based cities. But due to the longterm high- strength and extensive development, so many problems happen in the development of the mineral resource. Among these, the environment negative externality of the surface collapse, destroy of the vegetative cover and the discharge of the dust is especially serious.

\section{B. The Negative Externality of the Development of the Mineral Resources.}

The negative externality of the development of the mineral resource means the economic activity of the mining entity causes the extra economic lost to the other economic entity and the society. The negative externality in the development of 
the mineral resource mainly contains the negative externality of the environment and the negative externality of the safety.

1) The Negative Externality of the Environment: In the development of the mineral resource, the environment was impacted. But the executor did undertake the cost for eliminating the adverse effect brought to others. Therefore his private cost is lower than the social cost. And the manufacturer determines the production turnout according to the maximization of the private profit instead of the maximization of the social welfare. Socializing the private cost leads to serious negative externality. (See Fig 2). In figure 1, MSC and MPC represent the marginal social cost and marginal personal cost respectively. DD1 represents need. If we want to realize the maximization of the social welfare, the point of equilibrium shall be the cross point of the marginal social cost and the curve of the need. That is to say, to manufacture at E1 point. At this time, the price is PS, and the turnout is QS. Despite the social welfare, the manufacturer will produce with the principle of maximization of the private profit. In this case, the point of equilibrium is at the cross point of the marginal personal cost and curve of the need, that is, point E. At this time, the price is $\mathrm{Pp}$, and the turnout is Qp. Obviously, the negative externality appears at this time. AE means the external cost produced when the turnout is Qp. It is all undertaken by the society. This means that the negative externality leads to excessive production and low price, and the external cost is transferred, bringing lost to the society. In the Fig2, the lost is shown as AE1E.

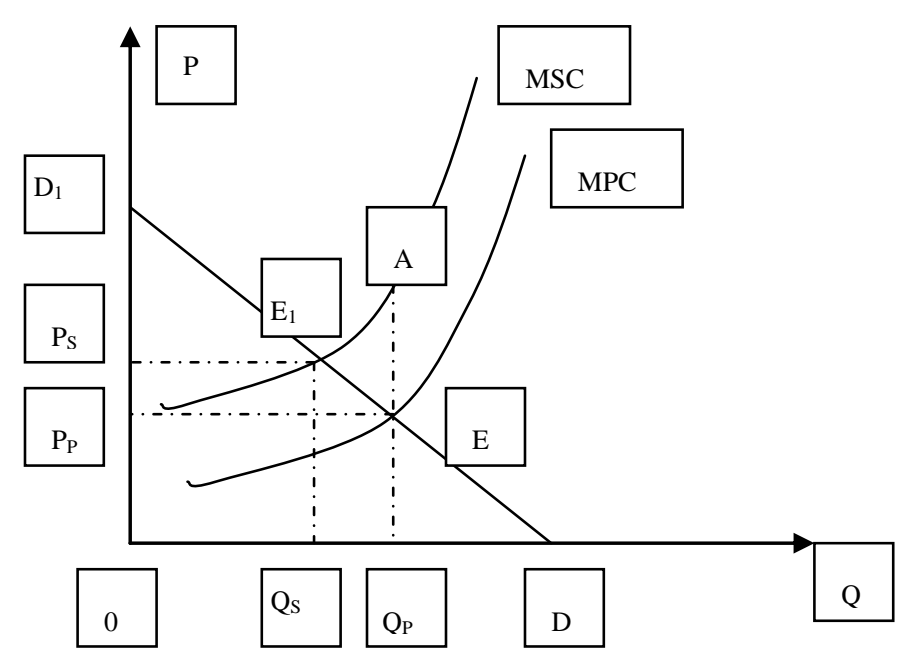

Fig 2 Negative externalities

During the course of developing the mineral resources, the negative externality mainly means the pollution to the environment.(See Fig3) The discharge of the rejected materials brings heavy pollution to the earth, the water and the air. At the same time, it brings the geologic hazard, destroys the ecological conditions. On the base of analysis of the Chinese mining industry construction changes, the Chinese Academy of Sciences Geographical Science and Resources Institute), with the gray model, predict the destroy situation of the earth resource caused by the Chinese mining industry from 1995 to 2010. The result shows that the lost for the excavated land is $23000 \mathrm{~km} 2$, the lost for the sunk land is $641000 \mathrm{~km} 2$, and the lost for the tied up land is $698000 \mathrm{~km} 2$. During the course of developing the mineral resources, the pollution to the water is prominently represented as the exploitation of petrol and gas, exploitation of the coal, and in the offshore oil drilling, the discharge of the waste water and the waste liquid covers over $10 \%$ of the discharge of the industrial waste water of all the country, while the treatment rate is only $4.23 \%$. The discharge of the industrial was gas from the exploitation of the coal all over the country is as high as 395,000,000,000 m3 each year. And the acid rain it caused reduces the grain yield by $10 \%$ each year. According to incomplete statistics, the secondary geological disaster of land sinking, mud-rock flow, water loss and soil erosion caused by the unreasonable exploitation destroys the land of over 100,000 hectares in total all over the country. Each year, nearly 1,000 people die of this. And the economic lost is up to $20,000,000,000 \mathrm{RMB}$.

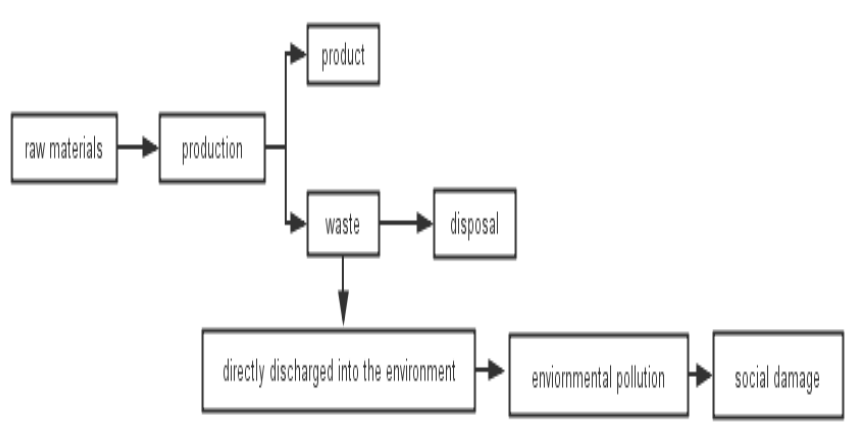

Fig 3: The environmental pollution and extern al diseconomy [3]

2) The Negative Externality of Safety: The negative externality of safety means that the unsafe activity will affect the employee, the owner of the enterprises, other people and the society, but the enterprises do not be responsible for all the cost caused by the unsafe activity (accident). It is the negative externality of safety makes the cost for the lost safety extremely tortuous. The actual cost for the accident is larger than the cost for the lost of safety. This also leads to the vicious circle of the safe production: the negative externality of safety leads to the serious deficiency of safety supply, and the deficiency of safety supply leads to the frequent occurrence of the safety accident. Both the impact on economic and the impact on society are very large.

The negative externality problems happen in the development of the mineral resources are mainly from the two aspects of the failure of the market and the failure of the government. The market failure is mainly caused by the indistinct definition of the right of the mineral resource and the publicity of the environment. And the failure of the government is represented as the unsymmetrical information, emphasizing the building of the system which is directly 
connected with the environment. While for the building of the related indirect system, the attention is deficient. Therefore, for the negative externality problem happens when developing the mineral resources, we shall effectively administrate with target, minimizing its impact and realizing the consistent development. One of the most effective administrating methods for the negative externality is to internalize it.

\section{The Analysis on the Method of Internalize the Negative Externality}

The nature of the negative externality is the socialization of the private cost. Therefore, the problem of the externality shall be solved fundamentally. Normally, there are three ways: utilizing the power of the government, utilizing the power of the market, utilizing the combination power of the market and the government.

\section{A. Power of the Government}

The power of the government focuses on the control level of the pollution, controls it to the minimum acceptable level and range, requires the Individuals and enterprises to internalize the negative externality and therefore reduces the production of the harmful product or discharge of the harmful substance. It is a treating method after pollution and a way of internalization after occurring.[4]

\section{B. Power of the Market}

The most outstanding representative for solving the problem of the negative externality with the market method is the property right negotiation theorem suggested by Kos. That is through the specification of the property right, the two parties or multi parties that are related to the external influences will negotiate to merge two or more factories and internalize the external influences. If the production of one enterprise affects the production of another enterprise, and if the effect is positive, the production of the first enterprise will be lower than the social optimal level; on the contrary, if the effect is negative, the production of the first enterprise will be higher than the optimal level. However if we merge the two enterprises into one enterprise, at this time, the external influence will "disappear". That is to say, it is "internalized".

\section{The Combination of the Government and the Market}

It is limited to solve the negative external problem with only the power of the market or the government. Only when the two are combined together, the market mechanism can be recovered, the negative externality can be efficiently resolved, and the pollution can be controlled at the satisfactory level. Therefore, the other method for resolving the negative externality is to combine the market with the government. That is, to constitute the rules for the transaction of the pollution right.

\section{Acknowledgment}

This work was financially supported by Innovation Team of Enterprise Security Management of North China Institute of Science and Technology

\section{References}

[1] Buchanan, James; Wm. Craig Stubblebine (November 1962): "Externality". Economica29 (116): 371-384.

[2] Xinmeng Huang and Hongwei Cheng and Qianying Feng: Journal of Chengdu University of Technology (Social Sciences), Vol.20 No.1 Jan. 2012,P49

[3] Yanmei He and Jianhong Chen: Resources Environment\& Engineering, Vol. 21 No. 2 Apr. 2007, P208

[4] Youzhi Liu: Economic Rrview No. 3 2001,P7 